\title{
Integration of Logistics Simulation Technology and Logistics Learning Factory in a Two-stage Teaching Method for Logistics Management Courses
}

\author{
https://doi.org/10.3991/ijet.v12.i09.7485 \\ Haiwei Fu \\ Ningbo University of Technology, Ningbo, China \\ richard_0518@hotmail.com
}

\begin{abstract}
Traditional classroom teaching techniques for logistics management courses focus solely on imparting theoretical knowledge despite the multidimensionality and diversity of the logistics working environment. Moreover, the application of modern teaching techniques is isolated and lacks systematic coordination. Students thus acquire knowledge but cannot adapt to practical working requirements. Therefore, to develop the autonomous learning ability of students and to improve teaching results of logistics management courses, this study proposes a two-stage teaching method that integrates logistics simulation technology and logistics learning factory. First, students are acquainted with various logistics operation links through logistics simulation technology, thus allowing students to exercise their abilities to autonomously design logistics systems and operate logistics system flow. Second, through the logistics learning factory, students experience the overall process of lean production and improve their learning interests through scenario rendering and visualization. Finally, the degree of the students' acceptance of this teaching method was surveyed on the basis of the technology acceptance model. Results showed that the students who were taught using the two-stage teaching method have significantly higher scores for perceived usefulness, attitude toward using, and behavioral intention than students who were not taught with the proposed method. The proposed two-stage teaching method compensates for the limitations of the single teaching method for logistics management courses. Nevertheless, its perceived ease of use should be improved.
\end{abstract}

Keywords-logistics simulation technology, logistics learning factory, technology acceptance model

\section{Introduction}

The logistics industry provides material and service production services to primary, secondary, and tertiary industries. Improving logistics management is crucial to improve production efficiency, reduce production costs, and boost industrial development [1]. Logistics management courses are particularly important for students who are majoring in logistics. These courses help students master the basic theories and 
methods of modern logistics and to familiarize themselves with the operation and management of logistics enterprises. The teaching contents of logistics management courses contain multiple links, such as purchasing, transportation, storage, loading and unloading, carrying, packaging, distribution, and recycling. Students should master the overall management of material, information, and fund flows.

Most colleges and universities have adapted to the growing demand for talent in the logistics industry by establishing logistics specialties and management courses. Most traditional teaching methods for logistics management courses focus on outdated classroom teaching with simple teaching processes that fail to retain the students' interest. In pure classroom learning, students have difficulty in intuitively comprehending real logistics operation statuses and teaching is disconnected from the real employment practices of enterprises. With the continuous development of computer technology, advanced processes, such as automated operation and lean production in logistics, are increasingly applied in factories. Therefore, many colleges and universities have begun to apply logistics simulation technologies in logistics management courses to satisfy the demand of employers for employees who are adept in the development, design, and management of logistics operations. However, single logistics simulation teaching remains at the simulation level with a certain gap between real logistics production practice. The operating environment of the logistics industry is multidimensional and diverse [2]. Therefore, to improve the effectiveness of logistics management courses, help students master professional skills in logistics management, and improve the relevance of classroom learning to actual work, this study integrates logistics simulation technology and logistics learning factory in the teaching practice of a logistics management course.

\section{State of art}

The logistics management course is highly practical. Many scholars have attempted to improve the teaching effect of logistics management courses to enable students to adapt to cultural requirements and have proposed methods that deserve reference. $\mathrm{Hu}$ utilized a problem-based teaching method to teach logistics management. To motivate autonomous learning interest and subjective initiative among students, the problem consciousness of the students is developed through scenario creation; enlightening and findings; assumption proposals; discussion and exploration; migration and application; and evaluation and conclusion [3]. However, this teaching method does not completely disregard the traditional teaching pattern and instead only improves classroom teaching without training students in the practical application of knowledge. Mo applied information-based teaching in logistics specialty teaching. The information-based teaching method is implemented before, during, and after teaching to improve the information level of teaching resources, teaching equipment, teaching aids, and teaching platform [4]. Although the information-based method is not highly professionally relevant, this method can improve the modernization level of logistics management teaching. However, the information-based method has nei- 
ther substantially improved professional teaching effect nor combined the teaching features and professional needs of logistics management courses.

With the continuous development of information technology, simulation technology has gradually matured as an important technical tool [5]. The application of simulation technology is ideal for improving the effectiveness of teaching logistics management. Tvrdon̆ and Jurásková introduced the application of simulation technology software in logistics teaching. Students can design every link in a logistics system operation or establish a model through this software and manage the operation of the whole logistics model using data to control price, equipment, and investment. [6]. The application of logistics simulation technology has helped students reject the traditional learning method and enabled the simulation of logistics operations through computer technology. However, single logistics simulation teaching remains far from the logistics operation environment in a real factory. Hofmann et al. added the virtual debugging process to logistics simulation technology [7]. Virtual debugging can improve the engineering control of logistics operations. Although virtual debugging is closer to the real logistics operation processes of enterprises and improves the learning experience of students, it cannot solve the problem of practical experience in a logistics environment. Brenner and Hummel introduced a logistics learning factory in Reutlingen University. The logistics learning factory created a completely real logistics operation environment through digital and physical integration [8]. The visualized teaching process and real coordinating interaction environment can greatly improve the students' learning experience level. Although the logistics learning factory has solved the learning experience problem, it discounts the teaching effect given the lack of early-stage knowledge reservation and learning preparation.

The application of modern logistics techniques in current teaching methods for logistics management remains weak. The lack of integrative teaching methods isolates the application of some existing teaching techniques and cannot comprehensively develop the abilities of students. Therefore, in this study, logistics simulation technology is integrated with logistics learning factor to develop a two-stage logistics management teaching method. This method sufficiently assimilates the advantages of the two teaching methods to improve teaching effects and compensate for the deficiencies of the single teaching method.

\section{Two-stage teaching method integrating logistics simulation technology and logistics learning factory}

Simulation technology has been extensively applied in various fields, such as economics, management, transportation, and commerce [9]. Simulation technology has been applied in warehousing, inventory, production, distribution center, port, and supply chain logistics [10]. Logistics simulation technology can assist in the design, planning, operation, and management of logistics systems to provide effective management and decision-making bases for logistics managers [11]. Logistics simulation teaching can help students discard the traditional teaching pattern, which solely focuses on imparting instructions and knowledge. Logistics simulation teaching can 
help strengthen the students' application ability, operational ability, and creative thinking, thus improving their abilities to solve practical problems.

The logistics learning factory is a teaching scenario with material objects. The learning factory can exist in the forms of laboratories or real enterprises. The real presentation of an actual operation scenario seamlessly joins teaching and practice. Lean production and operation procedures can be mastered through visualized operation for the extensive experience of logistics production and operation. Students can identify deficiencies in theoretical teaching during learning in a logistics learning factory. In addition, they can identify problems in actual logistics operations using their self-mastered fundamental knowledge of logistics.

The proposed two-stage teaching method is not a simple addition of logistics simulation technology and logistics learning factory but is instead an integration of these two methods. The proposed method thus achieves the " $1+1>2$ " teaching effect through mutual coordination. The specific teaching pattern is shown in Fig. 1.

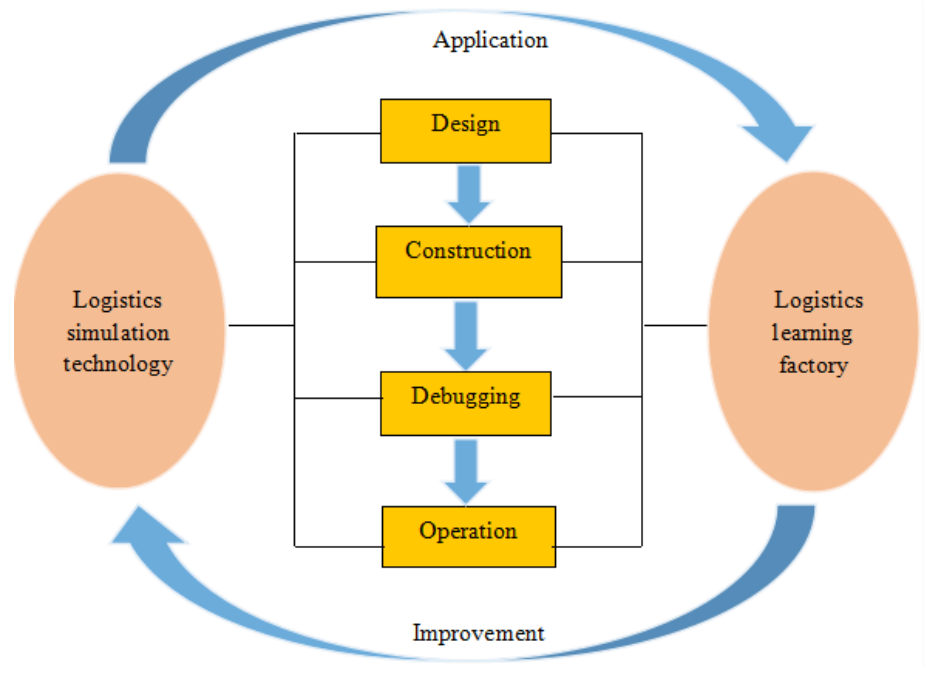

Fig. 1. Two-stage teaching pattern

Figure 1 shows that the logistics simulation technology allows students to develop excellent systematic thinking ability and provides theoretical technical reserve for practice in the logistics learning factory. Meanwhile, the logistics learning factory can be used to verify various logistics operation schemes during simulated learning and to provide a basis for further logistics system development. The integration of logistics simulation technology and logistics learning factory can enrich the teaching of logistics management and increase the students' interest in learning about logistics management. In addition, the two-step method can encourage students to actively use multiple learning tools and to motivate their innovative design thinking and ability. The prosed teaching method compensates for the deficiencies of traditional teaching, specifically for the poor practical ability of students, and is consistent with the present requirements for logistics talents. 


\section{Teaching case and teaching effect}

\subsection{Teaching case}

Warehouse management and lean production are important topics of logistics management courses. A case is presented to illustrate the implementation of the two-stage teaching method.

Logistics simulation link. RaLC-Pro logistics model simulation software can be used to establish a basic model of warehouse management. The model is established in three steps: (1) the construction of the conveyor system; (2) the construction of the storage system; and (3) the construction of the cohesion segment.

The conveyor system is designed on the basis of theoretical knowledge of good conveying: (1) the selection of the conveyor; (2) the connection of the conveyor; and (3) the setting of attributes. Connecting conveyor objects include the connection between conveyor belts and connection between the conveyor belt and cage trolley, as shown in Fig. 2 (a) and Fig. 2 (b).

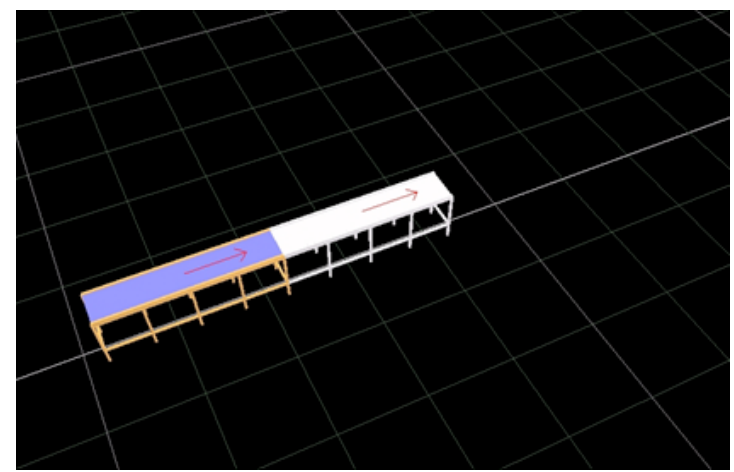

(a) Connection between conveyor belts (Source: RaLC-Pro software)

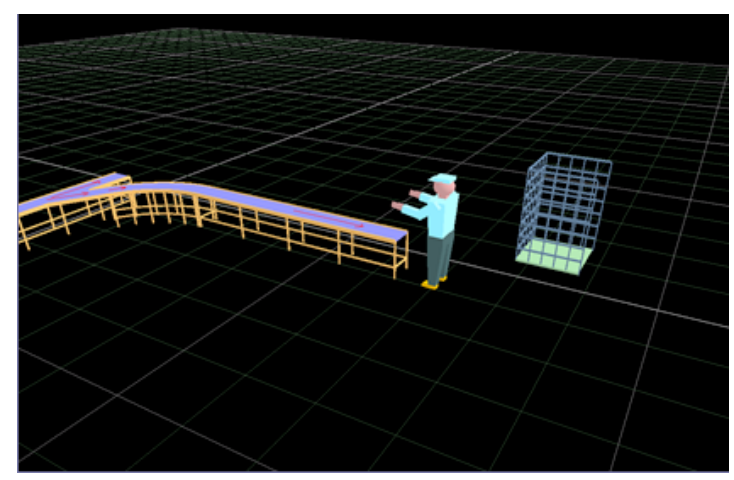

(b) Connection between conveyor belt and cage trolley (Source: RaLC-Pro software)

Fig. 2. 
To satisfy the requirements of good flow distribution, the conveyor belt could be set at a certain angle as shown in Fig. 3. A certain quantity of components could be inputted as shown in Fig. 4. Thus, a complete conveyor system could be established as shown in Fig. 5.

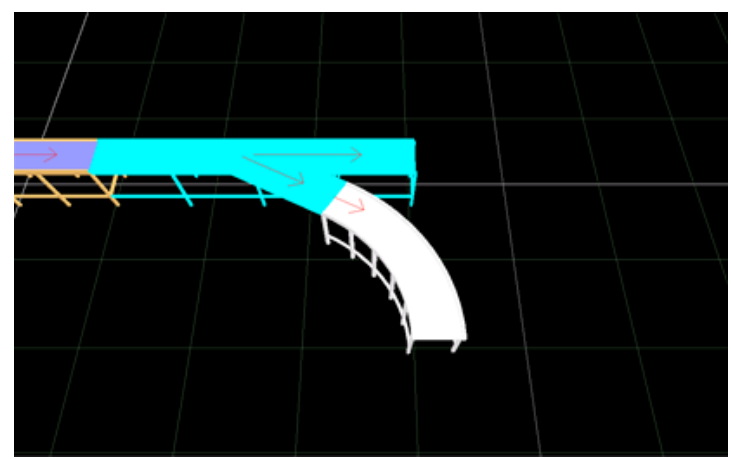

Fig. 3. Conveyor belt set at an angle (Source: RaLC-Pro software)

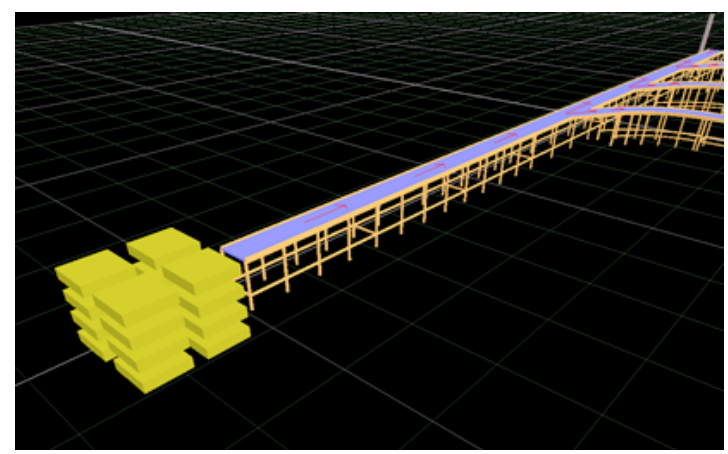

Fig. 4. Component input (Source: RaLC-Pro software)

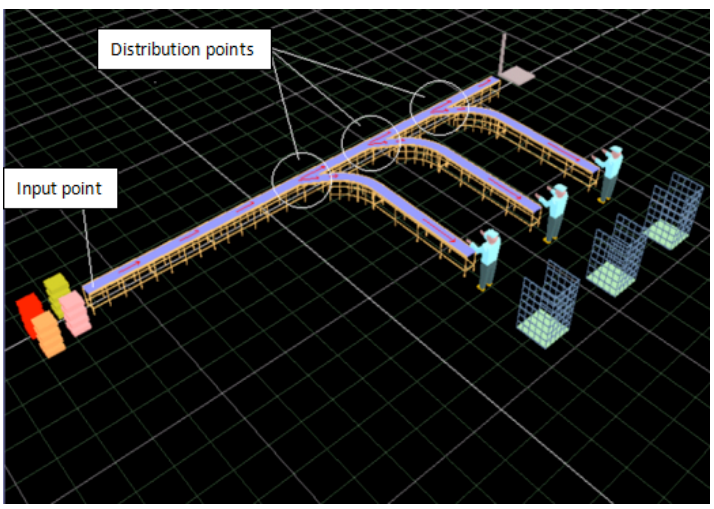

Fig. 5. Conveyor system (Source: RaLC-Pro software) 
The storage system was established on the basis of the theoretical knowledge of warehouse management, including (1) the selection of a stereoscopic warehouse as shown in Fig. 6 and (2) the warehouse port setting as shown in Fig. 7.

As shown in Fig. 8, a complete warehouse management model could be established on the basis of the presented components together with the mechanical arm and transfer station.

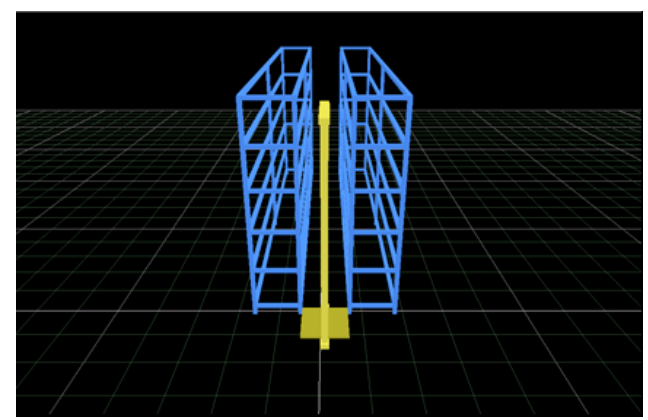

Fig. 6. Stereoscopic warehouse (Source: RaLC-Pro software)

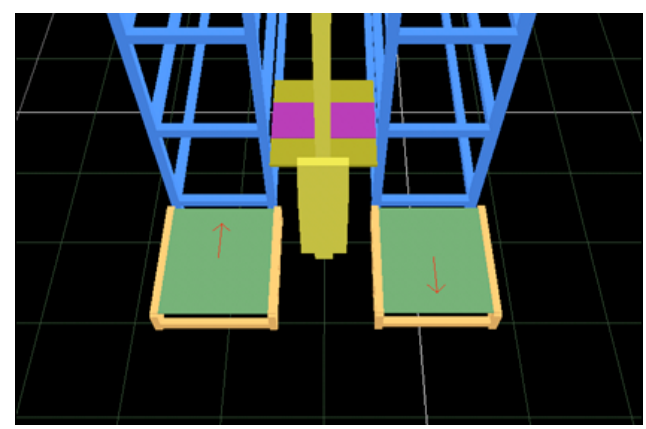

Fig. 7. Warehouse port setting (Source: RaLC-Pro software)

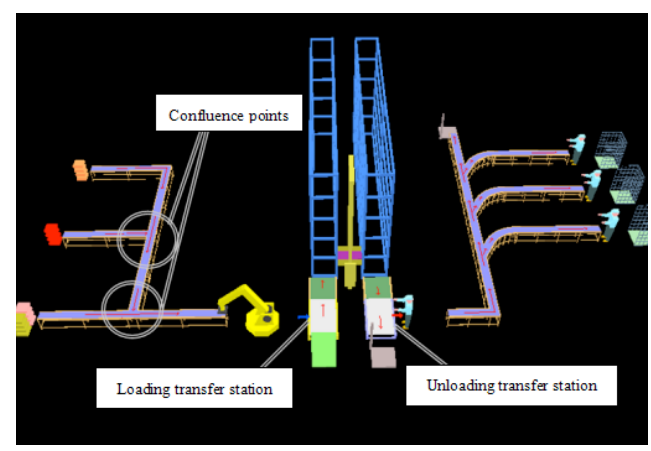

Fig. 8. Warehouse management model (Source: RaLC-Pro software) 
Links of the logistics learning factory. The students received practical experience with logistic links through the logistics learning factory. The students obtained a sufficient understanding of the basic theory and knowledge of warehouse management and lean production and learned the use of logistics simulation technology to autonomously design a logistics system model. In this course, the logistics learning factory was established inside the Ningbo High-Tech Zone, with professional logistics equipment suppliers for maintenance and upgrading as shown in Fig. 9 (a-b). The basic flow of the logistics learning factory is shown in Fig. 10.

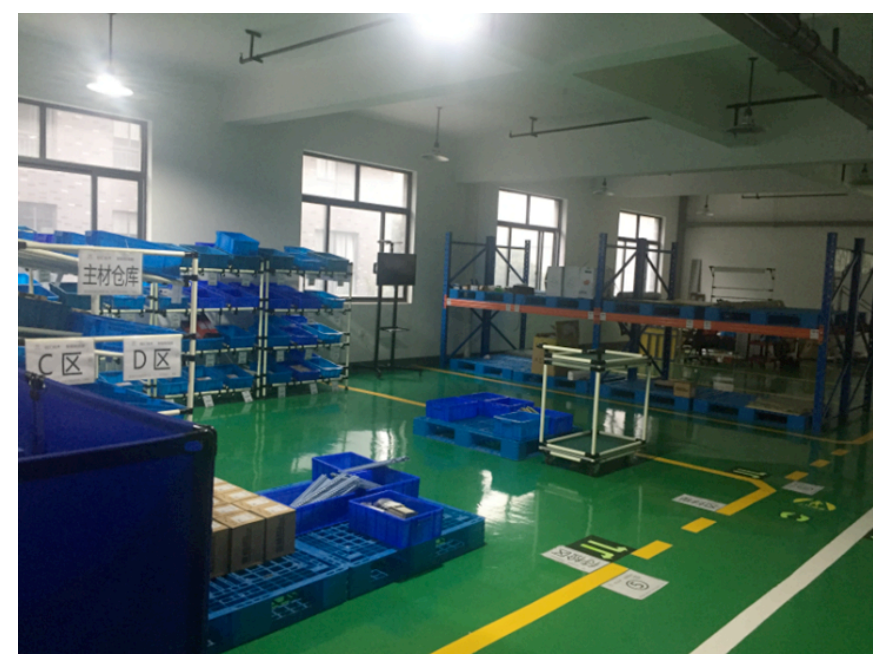

(a) Storage area

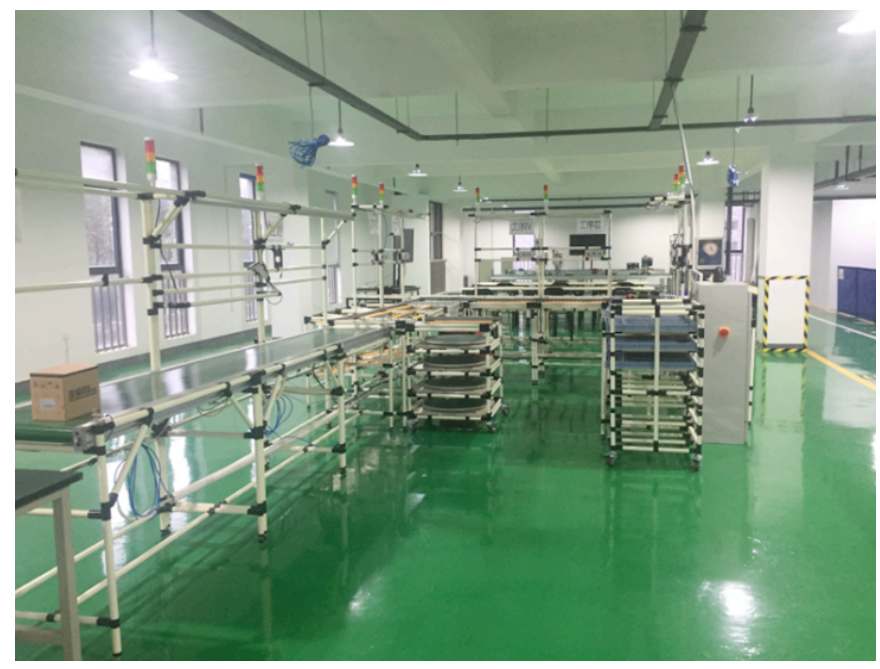

(b) Conveyor area

Fig. 9. 


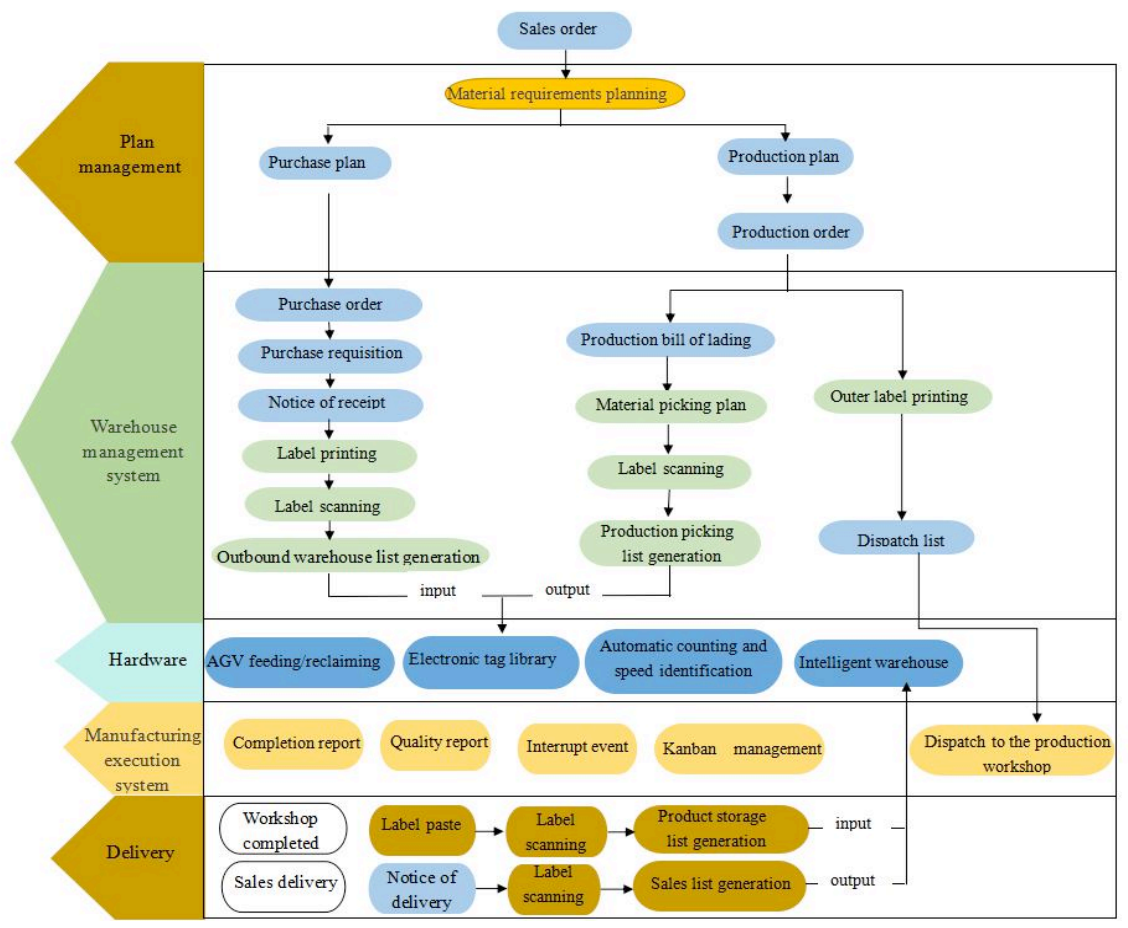

Fig. 10. Basic flow of the logistics learning factory

Students could understand the actual process of warehouse management and lean production through practical experience in the logistics learning factory, thus improving their abilities to analyze and solve practical problems. After their learning experience in the logistics learning factory, students could return to the laboratory to modify and improve the warehouse management model that was designed using logistics simulation software. This two-stage teaching pattern satisfies the students' need for autonomous learning and improves the learning effect of logistics teaching.

\subsection{Teaching effect}

A questionnaire survey was conducted to evaluate the concrete effect of two-stage teaching pattern on the basis of the basic indexes of the technology acceptance model. The survey was given to 160 students from 4 classes taught in 2016. Two innovation classes were taught using the two-stage teaching pattern, whereas the other two classes were taught using the traditional teaching pattern. The technology acceptance model was originally proposed to analyze user acceptance of information system through the rational behavior theory [12] and is widely applied in teaching research [13]. In accordance with the basic framework of the technology acceptance model, the survey included the main evaluation indexes of perceived usefulness, perceived ease of use, attitude toward using, and behavioral intention. The survey results are shown in Fig. 11. 


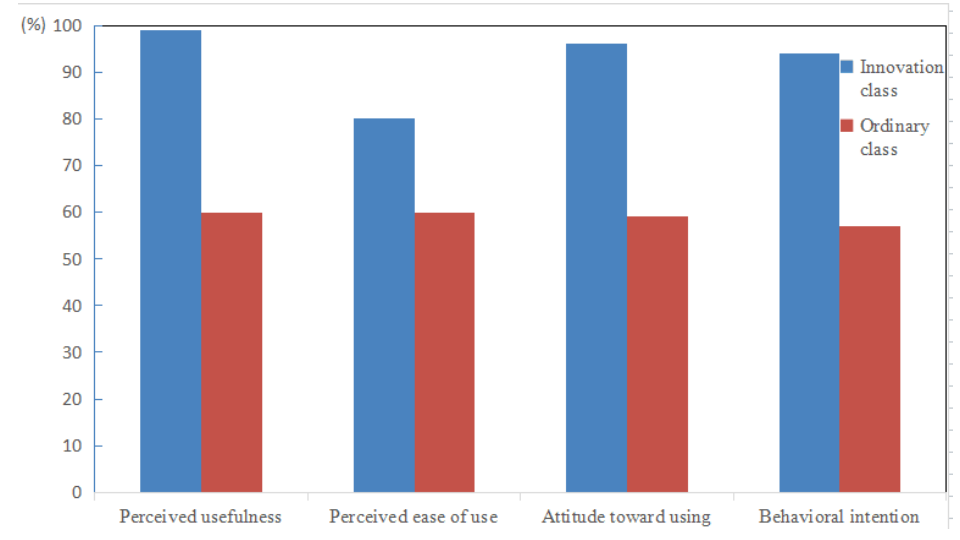

Fig. 11. Results of the questionnaire

According to statistical data in Fig. 11, the two-stage teaching method is more popular among the students than the traditional teaching method. The students perceived that the two-stage teaching method is more useful and exhibited a more positive attitude toward using and behavioral intention. However, some students reported deficiencies in the perceived ease of use of the proposed two-stage method because it simultaneously implements logistics simulation technology and logistics learning factory. Thus, some students who were accustomed to the traditional teaching pattern did not easily adapt to the proposed teaching method and found it more difficult than the traditional teaching method. Nevertheless, the two-stage teaching method was accepted by the students because it changed the traditional rigid teaching pattern and helped the students develop their autonomous innovation abilities.

\section{Conclusions}

This study proposed the two-stage teaching method for logistics management courses. The proposed teaching method integrates logistics simulation technology and logistics learning factory. The implementation of the proposed method was discussed in detail through a case. The positive effects of the teaching method were verified using a questionnaire survey that is based on the technology acceptance model. The main conclusions are as follows:

1. The two-stage logistics teaching pattern can improve the learning attitude and interest of the students, enhance the implementation effect of teaching, and compensate for the deficiencies of the traditional teaching pattern.

2. The two-stage logistics teaching pattern sufficiently combines the advantages of logistics simulation technology and logistics learning factory, thus helping students develop their autonomous learning ability and innovative design ability.

3. The two-stage logistics teaching method demonstrates logistics production and operation practice through practical exercises. However, its perceived ease of use requires further improvement. 


\section{References}

[1] E. Hofmann and M. Rüsch. Industry 4.0 and the current status as well as future prospects on logistics. Computers in Industry. 2017, vol. 89, pp. 23-34. https://doi.org/10.1016/ j.compind.2017.04.002

[2] I. Rügge and R. Klempien-Hinrichs. Coping with multi-dimensional diversity in logistics education. IFAC Proceedings Volumes. 2013, vol. 46, issue. 24, pp. 456-462. https://doi.org/10.3182/20130911-3-BR-3021.00101

[3] J. Hu. The Application of Problem - based Teaching Method in the Course of Logistics Management. Education Exploration. 2013, no. 4, pp. 45-46.

[4] Y. Mo. Research on Information Teaching Mode in Educational Reform of Logistics Specialty in Higher Vocational Education. Education and Vocation. 2015, no. 29, pp. 110-112.

[5] AS. Joel, M. Wang, C. Ramshaw and E. Oko. Modelling, simulation and analysis of intensified regenerator for solvent based carbon capture using rotating packed bed technology. Applied Energy. 2017, vol. 203, pp. 11-25. https://doi.org/10.1016/j.apenergy.2017.05.157

[6] L. Tvrdoň and K. Jurásková. Teaching simulation in logistics by using witness and captivate software. Procedia-Social and Behavioral Sciences. 2015, vol. 176, pp. 4083-4089. https://doi.org/10.1016/j.sbspro.2015.01.1158

[7] W. Hofmann, S. Langer, S. Lang and T. Reggelin. Integrating virtual commissioning based on high level emulation into logistics education. Procedia Engineering. 2017, vol. 178, pp. 24-32. https://doi.org/10.1016/j.proeng.2017.01.055

[8] B. Brenner and V. Hummel. A Seamless Convergence of the Digital and Physical Factory Aiming in Personalized Product Emergence Process (PPEP) for Smart Products within ESB Logistics Learning Factory at Reutlingen University. Procedia CIRP. 2016, vol. 54, pp. 227-232. https://doi.org/10.1016/j.procir.2016.06.108

[9] X. Ruan, J. Zhou, H. Tu, Z. Jin and X. Shi. An improved cellular automaton with axis information for microscopic traffic simulation. Transportation Research Part C: Emerging Technologies. 2017, vol.78, pp. 63-77. https://doi.org/10.1016/j.trc.2017.02.023

[10] T. Beinke, AA. Alla and M. Freitag. Resource Sharing in the Logistics of the Offshore Wind Farm Installation Process based on a Simulation Study. International Journal of eNavigation and Maritime Economy. 2017, vol. 7, pp. 42-54.

[11] N. Anand, D. Meijer, JHRV. Duin, L. Tavasszy and S. Meijer. Validation of an agent based model using a participatory simulation gaming approach: The case of city logistics. Transportation Research Part C: Emerging Technologies. 2016, vol.71, pp. 489-499. https://doi.org/10.1016/j.trc.2016.08.002

[12] FD. Davis, RP. Bagozzi and PR. Warshaw. User acceptance of computer technology: a comparison of two theoretical models. Management Science. 1989, vol. 35, no.8, pp. 9821003. https://doi.org/10.1287/mnsc.35.8.982

[13] CT. Chang, J. Hajiyev and CR. Su. Examining the students' behavioral intention to use elearning in Azerbaijan? The General Extended Technology Acceptance Model for Elearning approach. Computers and Education. 2017, vol. 111, pp. 128-143. https://doi.org/10.1016/j.compedu.2017.04.010

\section{$7 \quad$ Author}

Haiwei Fu is an associate professor in the International Port \& Logistics Research Center, Ningbo University of Technology, Ningbo 315211, China (richard_0518@hotmail.com).

Article submitted 27 July 2017. Published as resubmitted by the author 29 August 2017. 